\title{
SEPARAÇÃO DE PODERES E ATIVISMO JUDICIAL: LEGISLAÇÃO SIMBÓLICA E OS DIREITOS FUNDAMENTAIS
}

\section{SEPARATION OF POWERS AND JUDICIAL ACTIVISM: SYMBOLIC LEGISLATION AND FUNDAMENTAL RIGHTS}

\section{SIRLENE ELIAS RIBEIRO}

Advogada. Mestranda em Direito Empresarial e Cidadania pelo Centro Universitário Curitiba - Unicuritiba. Artigo como requisito para aprovação na matéria Intervenção do Estado e da Administração Pública na Atividade Econômica e Social. Contato: sirlene.elias@hotmail.com.

\section{RESUMO}

O presente artigo cuida de uma análise da atuação dos poderes Legislativo Executivo e Judiciário na realização e implementação dos direitos fundamentais previstos na Constituição Federal do Brasil. O Enfoque dado ao trabalho é a análise de considerações e definições doutrinárias acerca do tema proposto, bem como de julgados do Supremo Tribunal Federal, com o objetivo de uma conclusão acerca do crescimento do ativismo judicial e da judicialização das políticas públicas voltadas aos direitos humanos, passando por uma análise da elaboração de legislação simbolicamente e de uma atuação simbólica do Tribunal nas questões de direitos fundamentais.

PALAVRAS-CHAVES: Ativismo; Judicialização; Divisão de Poderes; Legislação Simbólica. 


\section{Personalidade Acadêmica Homenageada:}

\section{Carlos Aurélio Mota de Souza (Universidade Ibirapuera - UNIB)}

\section{ABSTRACT}

This article analyzes the performance of the Executive and Judiciary Legislative powers in the realization and implementation of fundamental rights foreseen in the Federal Constitution of Brazil. The focus of the work is the analysis of doctrinal considerations and definitions about the proposed theme, as well as of the Brasilian Federal Supreme Court, with the objective of a conclusion about the growth of judicial activism and the judicialization of public policies focused on human rights, through the analysis of the symbolic drafting of legislation and a symbolic role of the Court in matters of fundamental rights.

KEYWORDS: Activism; Judicialization; Division of powers; Symbolic Legislation.

\section{INTRODUÇÃO}

A nova ordem constitucional consolidada constituiu o Estado Democrático de Direito e trouxe uma série de questões novas. O Brasil saindo de um período ditatorial e reingressando num modelo de estado democrático teve o anseio de, em sua Constituição, conduzir o país a uma nova realidade, criar um estado justo e solidário, com crescimento econômico que busque diminuir as desigualdades sociais.

A Constituição designada "cidadã" traz em seu bojo rol extenso de direitos fundamentais a serem distribuídos a todos os cidadãos consolidando a divisão de poderes, tal como se conhece na teoria montesquiana ou numa releitura que hoje é percebida em alguns autores, especialmente ao analisada sob o enfoque do ativismo judicial e judicialização das políticas públicas, como o presente estudo vem abordar.

A concretização dos direitos fundamentais previstos na Constituição será objeto de análise no presente artigo na perspectiva da divisão dos poderes em uma pluralidade e circularidade de procedimentos, tanto no ativismo judicial como na judicialização, passando por uma consulta ao simbolismo da legislação, como forma de efetivação e eficácia dos direitos fundamentais. 


\section{Personalidade Acadêmica Homenageada:}

\section{Carlos Aurélio Mota de Souza (Universidade Ibirapuera - UNIB)}

O que se constatará ao longo do presente estudo é que muitas legislações existem e são elaboradas para postergar a resolução de um problema, satisfazer os desejos de determinados grupos e até mesmo se prestar como álibi ao legislador. Essa constatação auxiliará na identificação se os direitos fundamentais previstos na Constituição são efetivos e recebem a concretização ou apenas fazem parte do agir do legislador simbolicamente e até mesmo do Supremo, quando aplica e garante os direitos apenas a uma parte da população.

Será que é possível uma vinculação e ligação entre o ativismo judicial e a legislação simbólica? Eis a pergunta. Estariam os juízes fazendo o papel de justiceiros e aplicando a lei como deveria ser? Ou atuando de modo extensivo, indo para além do previsto? As respostas a estas perguntas, não restam claras, mas propõe uma reflexão sobre o tema que se mostra inquietante e latente frente ao crescimento de demandas judiciais discutindo e buscando a efetivação dos direitos fundamentais. Será que é plausível dizer que uma Constituição que não se aplica em sua plenitude é um terreno fértil para o ativismo judicial, onde o judiciário tem que interferir para concretizar valores e fins constitucionais? A essa indagação parece que a resposta seria afirmativa.

\section{DIVISÃO DE PODERES E PRINCÍPIO FUNDAMENTAL DO CONSTITUCIONALISMO MODERNO}

Inicia-se com breve apontamento acerca da divisão dos poderes, como princípio fundamental ao constitucionalismo moderno.

O modelo político, tal como hoje é conhecido e adotado na Constituição do Brasil, teve sua origem primária em Aristóteles. Os gregos já temiam o poder concentrado nas mãos de apenas um indivíduo como governante, o que tornaria a governabilidade mais difícil. Em Montesquieu a ideia de Aristóteles ganhou a forma que mais se aproxima do que é hoje observado. O poder do Estado dividido formando um modelo moderado, harmonizando os poderes cada um com sua força. (ARISTÓTELES, 1999, p. 248, apud SABINO, 2016, p. 37-38). 


\section{Personalidade Acadêmica Homenageada:}

Carlos Aurélio Mota de Souza (Universidade Ibirapuera - UNIB)

Montesquieu (1987, p. 7) em sua obra, estudou Política e Direito Constitucional cientificamente, aliás, pode-se dizer que foi um dos primeiro a fazer este estudo como ciência, utilizando como ferramenta de estudo e observação o método indutivo. Explica ter se baseado na indução: "De começo, examinei os homens, e concluí que eles, naquela infinita diversidade de leis e costumes, não eram conduzidos unicamente pela fantasia. Os meus princípios, não os tirei de meus preconceitos, mas da natureza das coisas". Nos anos em que se observou os indivíduos e a forma em que viviam contribuíram para a criação da teoria da divisão dos poderes estatais.

A teoria de Montesquieu, como a mais próxima à realidade ocidental moderna, o coloca como o pai da teoria de separação de poderes, apresentando a divisão dos poderes executivo, legislativo e judiciário. A doutrina desse filósofo, inspirada em uma reação radical ao absolutismo, pois não condescendia com as "formas mitigadas de limitação de poder". A separação de poderes, no consenso de grandes tratadistas, é que na teoria de Montesquieu há uma "distribuição efetiva e prática do poder entre os titulares" (BONAVIDES, 2007, p. 49).

Desde a Constituição de 1891, juízes tinham o poder para julgar a inconstitucionalidade de leis. Ao longo dos anos, especialmente em tempos de ditadura, os juízes perderam algumas garantias e sofreram algumas limitações ao seu poder de julgamento (SARLET; MARINONI; MITIDIERO, 2016, p. 259). Com a redemocratização, iniciada nos meados dos anos de 1980, novos horizontes surgiram, até que foi reunida a Assembleia Nacional Constituinte, sendo que em 05 de outubro de 1988 fora promulgada a Constituição vigente hoje no país, que tem como cerne a impossibilidade de a lei excluir da apreciação judicial lesão ou ameaça a direito.

$\mathrm{Na}$ divisão dos poderes, como forma de moderação harmônica entre os poderes, o Estado brasileiro se organiza, cabendo ao judiciário utilizar seu poder para aplicar as leis e as normas, é o clássico aplicar a lei exigindo o seu pronto e eficaz cumprimento. Ao legislativo cabe a elaboração das leis e ao executivo a administração geral do Estado, a promoção de políticas públicas, com o intuito de promover o bemestar social, dando cabo às suas disposições e aplicando o previsto na lei. $A$ Constituição Federal ao descrever em seu Artigo 2º que "São Poderes da União, 


\section{Personalidade Acadêmica Homenageada:}

\section{Carlos Aurélio Mota de Souza (Universidade Ibirapuera - UNIB)}

independentes e harmônicos entre si, o Legislativo, o Executivo e o Judiciário" remete a esse caráter de harmonia e interdependência entre os poderes.

Marcelo Neves em uma releitura à clássica teoria de Montesquieu apresenta que é mais adequado falar em "pluralidade e circularidade de procedimentos do Estado de Direito". Para Neves "O Estado Democrático de Direito legitima-se problematicamente através da conexão circular e conflituosa entre procedimentos eleitoral, legislativo-parlamentar, jurisdicional e político-administrativo". Nessa releitura há privilégio à ideia de que os procedimentos sejam distintos, no entanto, estes poderes interagem entre si, conectando-se (NEVES, 2008, p. 186).

\section{DIREITOS FUNDAMENTAIS CONSTITUCIONAIS}

O Brasil sai de um período ditatorial e reingressa no modelo político democrático com a Constituição de 1988. Essa Comnstituição veio com a intenção de mudança, conduzindo a um Estado Democrático, justo e solidário, com crescimento econômico, erradicação da pobreza, minimização das desigualdades sociais e maximização das oportunidades. Acontece que a mudança de um país não acontece de um dia para o outro e não foi diferente no Brasil, mesmo com uma constituição com diversos dispositivos prevendo garantias e direitos sociais a todos. O que se vê, são os ideais constitucionais distantes da realidade da grande maioria dos destinatários da lei suprema.

A dignidade da pessoa humana, no âmbito da evolução constitucional, não foi reconhecida de imediato. No Brasil, em comparação com outros países, a demora não foi tão expressiva, embora possa-se pensar que não haja uma efetivação do reconhecimento da dignidade, mas, isso não quer dizer que não tenha sido reconhecido, como será visto mais adiante.

A Constituição Federal de 1988 inseriu no primeiro título do texto constitucional em seu Artigo 10: "A República Federativa do Brasil, formada pela união indissolúvel dos Estados e Municípios e do Distrito Federal, constitui-se em Estado Democrático de Direito e tem como fundamentos: (...) III - a dignidade da pessoa 


\section{Personalidade Acadêmica Homenageada:}

Carlos Aurélio Mota de Souza (Universidade Ibirapuera - UNIB)

humana", muito embora já na Constituição de 1934 a sua primeira aparição já podia ser percebida, num contexto de ordem econômica (SARLET; MARINONI; MITIDIERO, 2016, p. 259).

A dignidade da pessoa humana estampada na Constituição no rol dos direitos fundamentais do Estado Democrático de Direito aparece também em outras partes do texto constitucional (SARLET; MARINONI; MITIDIERO, 2016, p. 259). Com a inclusão da dignidade humana nos Fundamentos do Estado Democrático de Direito, reconheceu-se que o Estado existe em função da pessoa humana, e não ao contrário. A partir desta premissa, o Estado passa a servir de instrumento para garantir a promoção da dignidade individual e coletivamente.

O que se depreende da Constituição é a ideia da universalidade e distribuição dos bens comuns, como agente catalizador para promover a inclusão social, por promover e tornar realidade a dignidade da pessoa, efetivando os direitos sociais, passando, necessariamente, por questões econômicas. Aquilatado junto aos índices de crescimento do Brasil, ainda não se pode visualizar a verdadeira eficácia dos direitos e garantias, que amparam a dignidade da pessoa humana, constatando-se uma situação paralela e próxima a de países com índices econômicos inferiores aos do Brasil. É essa realidade que atinge a maioria dos cidadãos. É por assim dizer, um Constituição distante da realidade da maioria dos seus cidadãos e, portanto, simbólica.

As constituições nominalistas apresentam os direitos humanos de forma textualizada nos documentos constitucionais. Esta particularidade mostra uma função "eminentemente simbólica e não contribui, de um modo relevante para a força normativa dos direitos humanos" (NEVES, 2005, p. 18). Verifica-se que as normas referentes aos direitos humanos são constantemente vilipendiados em sua concretização, razão pela qual carecem de eficácia, em face da enorme exclusão social de grande parte da população no gozo dos direitos humanos constitucionalmente garantidos. Sendo a aplicabilidade destes direitos in totum um privilégio destinado a uma parcela minoritária da população.

Não se deve perder de vista que as normas constitucionais possuem eficácia jurídica dada a sua natureza, não se trata de meros conselhos, antes são constituídas 


\section{Personalidade Acadêmica Homenageada:}

Carlos Aurélio Mota de Souza (Universidade Ibirapuera - UNIB)

de força imperativa. Cabe então distinguir eficácia jurídica de eficácia social da norma, que é a concretização do comando normativo, sua força operativa no mundo dos fatos. A eficácia social passa pela efetividade, como o mecanismo para sua implementação. A efetividade vem a ser a realização do direito, representa materialização no mundo dos fatos, dos preceitos legais e simboliza a aproximação do "dever-ser" normativo e o "ser" da realidade social (BARROSO, 2002, p. 84-85).

Convém aqui lembrar que a Constituição, chamada de Cidadã, traz em seu conteúdo a garantia dos direitos fundamentais, no entanto, o que se vivencia é a falta de efetividade da lei que garante o acesso a esses direitos, configurando-se uma constituição simbólica, conforme nos mostra Marcelo Neves, que adiante colocar-seá alguma explicação acerca da tese por ele defendida.

\section{UMA LEGISLAÇÃO SIMBÓLICA}

Nas palavras de Marcelo Neves (2007, p. 30) pode-se definir legislação simbólica como "produção de texto cuja referência manifesta à realidade é normativajurídica", depreendendo-se assim a subserviência com a finalidade política.

Quando uma norma que determina uma conduta é adotada com fim único de que a conduta seja realmente observada, estar-se-á diante de um caso em que a função "normativo-jurídica, instrumental", sobrepõe-se à "político-ideológica, simbólica". Ao contrário, quando não se busca a observância da conduta materializada na norma, simplesmente a "finalidades político-ideológicas", pode-se dizer que a norma tem um significado latente, indireto e simbólico.

Pode-se definir legislação simbólica:

Evidentemente, quando o legislador se restringe a formular uma pretensão de produzir normas, sem tomar nenhuma providência no sentido de criar os pressupostos para eficácia, apesar de estar em condições de cria-los, há indício de legislação simbólica (NEVES, 2007, p. 31).

E prossegue o autor que: 


\title{
Personalidade Acadêmica Homenageada:
}

\section{Carlos Aurélio Mota de Souza (Universidade Ibirapuera - UNIB)}

\begin{abstract}
Quando, porém, a nova legislação constitui apenas mais uma tentativa de apresentar o Estado como identificado com os valores ou fins por ela formalmente protegidos, sem qualquer novo resultado quanto à concretização normativa, evidentemente estaremos diante de um caso de legislação simbólica. (NEVES, 2007, p. 33).
\end{abstract}

Como exemplo clássico trazido por Neves, abordado por Gusfield, de legislação simbólica é o caso da "lei seca" nos Estados Unidos. Os defensores da proibição de consumo de bebidas alcoólicas não tinham interesse na sua eficácia instrumental, mas em adquirir maior respeito social, "constituindo-se a respectiva legislação como símbolo de status". Nos conflitos entre "protestantes/nativos" que defendiam a lei seca e "católicos/imigrantes" que se mostraram contrários à proibição, a "vitória legislativa" teria funcionado simbolicamente "como ato de deferência para os vitoriosos e de degradação para os perdedores" (NEVES, 2007, p. 33-34). Convém lembrar que aos que defendiam a lei, não interessava se esta lei seria ou não cumprida, se haveria diminuição no consumo de bebida alcoólica, mas, antes Ihes interessavam a vitória e o status de ter uma lei aprovada, mesmo que simbolicamente.

A leitura da obra de Marcelo Neves (2017, p. 36) mostra que a legislação denominada simbólica pode ter como objetivo satisfazer as expectativas dos cidadãos, isso porque o legislador ao elaborar a lei está tentando dar aos cidadãos confiança no Estado. Nestas situações o legislador não está focado na efetivação das normas.

A legislação simbólica pode se classificar em três diferentes tipos, como exposto por Marcelo Neves:

a) Legislação como confirmação de valores sociais - a eficácia da lei fica para um segundo plano, o mais importante é o reconhecimento social dos seus valores. Aqui um grupo que luta por direitos sai vitorioso ideologicamente em relação ao outro, mesmo a lei não tendo eficácia, vez que o que importa é a confirmação dos valores sociais. A legislação simbólica destinada a "confirmação de valores sociais tem sido tratada basicamente como meio de diferenciar grupos e os respectivos valores e interesses" (NEVES, 2007, p. 35);

b) Legislação álibi - o legislador se interessa em fazer uma lei para satisfazer os anseios da população, sem se preocupar em vê-la efetivamente 


\section{Personalidade Acadêmica Homenageada:}

\section{Carlos Aurélio Mota de Souza (Universidade Ibirapuera - UNIB)}

cumprida, muitas vezes essa lei é feita sob pressão para acalmar os ânimos da população frente a alguma situação de comoção nacional, revolta ou mesmo de uma tragédia. É o que Neves, com esteio em Kindermann (Apud NEVES, 2007, p. 39), apresenta em sua tese. A legislação simbólica com fins de álibi apresenta-se para dar aparência de confiança e solução dos problemas sociais e dar ao cidadão a visão de que o Estado tem boas intenções, que é sensível às exigências e às expectativas dos cidadãos. O que não se pode perder de vista é que essa forma de legislação não soluciona problemas, muito pelo contrário, ela obstaculiza as soluções. A legislação álibi é "uma forma de manipulação ou de ilusão que imuniza o sistema político contra outras alternativas" (NEVES, 2007, p. 39-40).

c) Legislação como compromisso dilatório - aqui se observa que as questões divergentes entre grupos políticos não são resolvidas por meio de ato legislativo. Antes, consensualmente entre as partes envolvidas, há previsão de que a lei terá ineficácia, mas essa ineficácia é que faz com que ambos os grupos façam um "acordo" em torno do seu conteúdo, postergando a resolução do conflito. "O acordo não se funda então no conteúdo do diploma normativo, mas sim na transferência da solução do conflito para um futuro indeterminado" (NEVES, 2007, p. 41).

Pela análise do exposto, constata-se que o processo de legislação simbólica implica na sobreposição do sistema político sobre o jurídico e consequentemente a falta de concretização das normas. Adiante far-se-á uma análise do crescente aumento das demandas que chegam ao judiciário buscando a concretização de políticas públicas e anseio pela efetivação de direitos fundamentais. Estaria essa demanda relacionada com a falta de efetividade de legislação que tiveram a sua origem simbolicamente? Essa é uma correlação real ou não? Eis uma pergunta latente!

\section{ATUAÇÃO DO PODER JUDICIÁRIO}

O Poder Judiciário possui uma atuação em momento posterior, ou seja, age não na implementação das políticas voltadas à promoção do bem-estar e da 


\section{Personalidade Acadêmica Homenageada:}

Carlos Aurélio Mota de Souza (Universidade Ibirapuera - UNIB)

concretização dos direitos fundamentais, certo é que a sua ação ocorre quando constatado a inércia estatal na proteção a esses direitos. A Administração Pública, titular do dever de promover políticas públicas, quando não age deixa espaço vago para atuação do judiciário, não para este cumprir o papel da administração, mas para fazer com que a Administração Pública cumpra a sua função e a efetividade da ação pode vir a ser chancelado pelo judiciário. (SCHWARTZ; BORTOLOTTO, 2008, sp).

A atuação do Poder Judiciário em atos da Administração Pública pode não configurar interferência de um poder sobre o outro, no momento em que sua atuação se apresenta como forma de correção e não prospecção. Esse controle de poderes é o que sustenta a democracia. O controle judicial não é ilimitado e demanda fundamentação, vez que é preciso trazer a razoabilidade das decisões.

O Judiciário, muito embora não seja um poder originariamente nascido da vontade popular, quando atua, até sobrepondo a uma decisão do Presidente da República, o faz investido e legitimado do poder que a teoria constitucional normativa Ihe concede. Decorre da própria Constituição a atribuição ao poder Judiciário, especialmente ao Supremo Tribunal Federal, o poder de assim atuar. O que não se pode perder de vista é que a sua atuação é de forma técnica e imparcial.

Assim, pode-se afirmar que:

[...] magistrados não têm vontade política própria. Ao aplicarem a Constituição e as leis, estão concretizando decisões que foram tomadas pelo constituinte ou pelo legislador, isto é, pelos representantes do povo. Essa afirmação, que reverencia a lógica da separação de Poderes, deve ser aceita com temperamentos, tendo em vista que juízes e tribunais não desempenham uma atividade puramente mecânica. Na medida em que lhes cabe atribuir sentido a expressões vagas, fluidas e indeterminadas, como dignidade da pessoa humana, direito de privacidade ou boa-fé objetiva, tornam-se, em muitas situações, co-participantes do processo de criação do Direito." (BARROSO, 2012, p. 28).

\section{O ATIVISMO JUDICIAL E A JUDICIALIZAÇÃO}

Pode-se dizer que entre o ativismo judicial e a judicialização haja uma conexão, uma espécie de parentesco, que nos dizeres de Barroso são "da mesma 


\section{Personalidade Acadêmica Homenageada:}

Carlos Aurélio Mota de Souza (Universidade Ibirapuera - UNIB)

família". O que separa um fenômeno do outro é a sua origem. A judicialização decorre do modelo constitucional adotado, enquanto o ativismo decorre de uma atitude, um modo de interpretar a Constituição, muitas vezes expandindo o seu alcance.

Nos dizeres de Luís Roberto Barroso (2012, p. 24) o judiciário deixou de ser um departamento técnico-especializado e se transformou em um verdadeiro poder político, capaz de fazer valer a Constituição e as leis, inclusive em confronto com os outros Poderes. Essa investidura do judiciário acentuou-se com a Constituição de 1988, com as garantias da magistratura e com uma geração de juízes pós período ditatorial. Nesse mesmo contexto observa-se a crescente atuação do Ministério Público, aliado a isso, pode-se afirmar que os cidadãos iniciaram uma fase de busca de seus direitos, batendo às portas do judiciário para ver seus anseios e necessidades atendidos nos moldes previstos na Constituição.

O ativismo pressupõe uma atuação mais "ampla e intensa do Judiciário na concretização dos valores e fins constitucionais, com maior interferência no espaço de atuação dos outros dois Poderes (BARROSO, 2012. p. 25). Nos últimos anos o que se vê é uma demanda crescente chegando aos tribunais, onde os titulares buscam a realização e efetivação dos seus direitos. Como consequência destas demandas, observa-se o incremento das funções distributivas pelo Judiciário.

O ativismo está ligado a uma ideia de proatividade na interpretação da Constituição, até mesmo expandindo o seu sentido e alcance afim de acompanhar a evolução jurisprudencial. Geralmente ocorrendo quando de uma omissão ou lacuna dos poderes Legislativo e/ou Executivo. Alguns autores, dente eles Lenio Streck (2004, p. 19-20, Apud ANDREASSA JUNIOR, 2015, p. 33) afirmam que a "omissão é chamada de síndrome da ineficácia das normas constitucionais". Esse mesmo autor não vê no ativismo algo bom.

A obra de Elival da Silva Ramos traz um conceito sobre ativismo judicial, o qual entende-se pertinente trazer, assim diz o autor:

Ao se fazer menção ao ativismo judicial, o que se está a referir é à ultrapassagem das linhas demarcatórias da função jurisdicional, em detrimento principalmente da função legislativa, mas, também, da função administrativa e, até mesmo, da função de governo. [...] da descaracterização 


\section{Personalidade Acadêmica Homenageada: \\ Carlos Aurélio Mota de Souza (Universidade Ibirapuera - UNIB)}

da função típica do Poder Judiciário, com incursão insidiosa sobre o núcleo essencial de funções constitucionalmente atribuídas a outros Poderes (RAMOS, 2010, p. 116-117).

Ainda em outra passagem:

[...] por ativismo judicial deve-se entender o exercício da função jurisdicional para além dos limites impostos pelo próprio ordenamento que incumbe, institucionalmente, ao Poder judiciário fazer atuar, resolvendo litígios de feições subjetivas (conflitos de interesse) e controvérsias jurídicas de natureza objetiva (conflito normativo). Há, como visto, uma sinalização claramente negativa no tocante às práticas ativistas, por importarem na desnaturação da atividade típica do Poder Judiciário, em detrimento dos demais Poderes (RAMOS, 2010, p. 129).

Eber Ferreira (2014, p. 13) coloca que há doutrinadores que enxergam no ativismo judicial uma atividade perigosa aos "postulados democráticos" e até mesmo um risco. Por outro lado, há aqueles quem visualizam o ativismo como uma atuação nova do poder judiciário, como forma de fortalecimento da democracia sob o viés de um "constitucionalismo mais adequado à realidade atual". Para este trabalho não se adentrará na análise pormenorizada destas correntes.

Cumpre assinalar que o ativismo judicial é visto por alguns doutrinadores como benéfico e legítimo. Para o grupo que defende esta linha de estudo, a separação de poderes deve ser revista e já não se sustenta no ordenamento jurídico atual, sobretudo porque foi elaborada em um Estado absolutista, sendo que nos dias atuais, em pleno século XXI, é preciso que haja mais interação entre os poderes e mais efetivação e eficácia das normas constitucionais, especialmente as que preveem e garantem os direitos fundamentais. (ANDREASSA JUNIOR, 2015, p. 31).

Há sempre perguntas que veem à tona quando se fala em ativismo. Luís Roberto Barroso (2009, p. 4, Apud ANDREASSA JUNIOR, 2015. p. 35) é quem traz indagação de quais seriam os motivos de haver tanto ativismo judicial. Seria essa força atuante, originária da vontade de Ministros preocupados com a concretização dos valores e princípios constitucionais? Ou, estar-se-ia diante de uma crise de funcionalidade do Poder Legislativo, que estimula a emissão de Medidas Provisórias pelo Executivo? Estas são as perguntas postas pelo citado autor! A resposta a estas 


\section{Personalidade Acadêmica Homenageada:}

Carlos Aurélio Mota de Souza (Universidade Ibirapuera - UNIB)

perguntas não parece ficar clara, mas o que parece incontestável, especialmente analisando a quantidade de demandas que chegam ao judiciário, indica que a incidência da omissão dos poderes legislativos e executivo, associado a ineficácia de muitas leis pode ser uma das causas da crescente atuação do Judiciário na implantação de políticas públicas e concretização dos direitos fundamentais.

Por outro lado, percebe-se que o cidadão assiste ao desmoronamento dos referenciais políticos-institucionais, com uma "descrença aos princípios éticos do agir político". Essa descrença gera a transferência das expetativas frustradas da população para o judiciário, ao ponto em que a busca pelos ideais de justiça é transferida e perseguida por outro prisma. Essa transferência se dá quando ao colocar na figura do juiz a esperança de conseguir e garantir seus direitos. Ao juiz cabe corrigir as injustiças, é a ele que a população pede "salvação". Com isso o juiz torna-se o "guardião das promessas, tanto para o indivíduo como para a comunidade política (GARAPON, 1998, p. 23, Apud BRASIL, 2014, p. 41).

Como dito alhures, a judicialização decorre do modelo constitucional adotado no Brasil. Oportuno dizer que a judicialização iniciou-se com o processo de redemocratização do país, cujo marco foi a promulgação da Constituição de 1988. Percebe-se que, com as garantias da magistratura, o Judiciário distanciou-se de uma atuação técnica especializada e aproximou-se de uma atuação política, inclusive confrontando com outros Poderes. O que se vê é uma migração de questões políticas ao judiciário para definir em última instância.

Nos dizeres de Vinicius de Melo Lima (2016, p. 95) a judicialização da política é um problema contemporâneo e contingencial, diferenciando-se do ativismo judicial, o qual afeta a "teoria da interpretação, na medida em que sua análise e definição dependem do modo como se olha para o problema da interpretação no Direito".

\section{ATUAÇÃO DO SUPREMO TRIBUNAL FEDERAL EM DIREITO FUNDAMENTAL}

Ao julgar direito à saúde, um dos direitos elencados no rol de direitos fundamentais, a atuação do Supremo tem como traço a não violação ao princípio da 


\section{Personalidade Acadêmica Homenageada: \\ Carlos Aurélio Mota de Souza (Universidade Ibirapuera - UNIB)}

separação dos poderes, no entanto, o Estado, com a intenção de deslegitimar a atuação do judiciário reclamou que o judiciário estaria a violar o princípio da separação dos poderes, tentando com essa argumentação barrar a atuação do judiciário ante a sua inércia e não cumprimento das suas funções. A Suprema Corte vê o direito à saúde como bem indisponível, mesmo diante de argumentos de escassez de recursos. Aqui coloca-se, exemplificativamente, as questões do mínimo existencial versus reserva do possível.

No Recurso Extraordinário 368.564/DF a União recorre pretendendo reformar o acórdão do Tribunal de Justiça que outorgou tratamento médico em Cuba. Neste acórdão houve um longo debate em que se defendeu o direito à saúde, concluindo ser um direito em desfavor do Estado, que a reserva do possível é uma desculpa.

Veja-se trechos do supracitado acordão:

Recurso Extraordinário 368.564/DF. Relator Ministro Marco Aurélio

Trecho do julgado, p. 85:

O SENHOR MINISTRO MARCO AURÉLIO (PRESIDENTE) - EsSa denominada reserva do possível, no tocante ao Estado, leva-me à indignação como contribuinte, como cidadão, como juiz, pois, se for realmente empolgada e aceita, teremos desculpa para tudo, porquanto, desde que me conheço, o Estado, em que pese à grande carga tributária, luta contra escassez de receita, mas luta porque tem despesas excessivas, principalmente com a máquina administrativa e a dívida interna". 107. Trecho do mesmo julgado, p. 87: "O SENHOR MINISTRO AYRES BRITTO - [...] Bem, se os direitos sociais, notadamente no campo da saúde, da educação, da assistência à adolescência e à infância, são direitos de crédito contra o Estado, demandam prestação contra o Estado, desembolso de recursos, é preciso atentar para o fato de que os recursos orçamentários são escassos e pesa contra esses direitos uma cláusula da reserva financeira do possível. Mas eu entendo que essa reserva financeira do possível seja uma desculpa cômoda por parte do Estado; é a mais cômoda das desculpas". 108. Trecho do mesmo julgado, p. 94: "A questão da intervenção judicial em políticas sociais está intimamente relacionada ao princípio da separação dos poderes, elemento central na acomodação do desenho institucional das democracias modernas.

Fernando Rister de Sousa Lima (2015) debruçou-se diante de julgados do Supremo Tribunal Federal, trazendo uma análise balizada e precisa sobre a saúde e os tribunais, não somente no campo da teoria, mas analisando consistentemente casos relevantes do Judiciário no Brasil. Marcelo Neves ao prefaciar a obra de 


\section{Personalidade Acadêmica Homenageada:}

Carlos Aurélio Mota de Souza (Universidade Ibirapuera - UNIB)

Fernando destaca a posição de Ingo Sarlet, quando convidado a participar da Audiência Pública do Supremo Tribunal Federal em 2009, que advertiu a necessidade de repensar a forma de garantir o direito à saúde.

A tese de Rister chama a atenção para o fato de haver um "superdireito" à saúde a uma parcela da elite, enquanto outra parcela fica à mercê, em exclusão social na condição de "subdireito" à saúde. Dado que o Supremo é incompetente juridicamente, ilegítimo politicamente e inapto tecnicamente para implementar políticas públicas de saúde, daí resulta que o STF não tem atuado como guardião do direito à saúde, mas como assegurador e intensificador de privilégios no acesso à saúde (NEVES, prefácio LIMA, 2015, p. 13-14).

A sociedade moderna está rodeada de possibilidades e opções, podendo escolher várias alternativas, sendo todas válidas. O direito enfrenta situações novas e novos desafios dia após dia, como se houvesse uma certa volatilidade de possibilidades. A sociedade é complexa e evolui constantemente, a partir do enfrentamento dos problemas que vão surgindo e das novas operações sociais que aparecem. $O$ direito não conseguirá resolver todos os problemas sociais eliminando os dissabores de uma vida complexa, sem um poder público efetivo e completamente tomado pela corrupção sistémica (LIMA, 2015, p. 56). Ao tribunal cabe dizer se a conduta é lícita ou não, e nesse contexto o tribunal tem feito seu papel.

Norberto Bobbio (1997, p. 63 apud LIMA, 2015, p. 48) traz uma advertência que se torna cada vez mais atual "[...] uma coisa é falar dos direitos do homem, direitos sempre novos e cada vez mais extensos, e justifica-los com argumentos convincentes; outra coisa é garantir-Ihes uma proteção efetiva. [...]". Acresce-se: "[...] à medida que as pretensões aumentam, a satisfação delas torna-se cada vez mais difícil".

Voltando um pouco sobre a questão da legislação simbólica, posta por Marcelo Neves, torna-se oportuno trazer as considerações de Fernando Lima (2015, p. 170) acerca da atuação simbólica do Supremo Tribunal Federal, para o qual a atuação simbólica do Supremo "caracterizar-se-á quando prevalecer na sua racionalidade jurídica o significado: político-ideológico em desfavor da concretização normativo-jurídica. A decisão simbólica, portanto, teria um escopo de álibi social". 


\section{Personalidade Acadêmica Homenageada:}

\section{Carlos Aurélio Mota de Souza (Universidade Ibirapuera - UNIB)}

Por outro lado, há a atuação efetiva do Supremo Tribunal Federal, que de igual forma, convém aqui trazer, uma vez que as normas constitucionais não são apenas conselhos, mas sim a base do direito e tudo decorre delas, por isso o seu conteúdo "é obrigação do Estado fazê-lo efetivar-se, inicialmente dentro do próprio sistema, para em seguida concretiza-lo socialmente (LIMA, 2015, p. 175). Com isso, conclui-se que o Supremo ao dizer e mandar aplicar a lei, exercerá sua atuação efetiva, fazendo com que haja o cumprimento da determinação, sob pena de sanções cabíveis ao descumprimento da decisão.

Diante da enorme quantidade de inadmissibilidade de recursos ao Supremo Tribunal Federal, torna-se possível fazer algumas observações: o fato da grande maioria dos recursos não serem admitidos, ou seja, não passarem pela porta do tribunal, faz com que muitos direitos deixem de ser analisados e concedidos, diante da inadmissibilidade do recurso. Não é de se estranhar que a maioria dos jurisdicionados não são assistidos por grandes juristas e por teses que façam "subir" os recursos, mas isso não significa que o cidadão não tenha direito. Com essa inadmissibilidade, sem análise se há ou não o direito, o Supremo apresenta uma atuação simbólica. Muitos jurisdicionados na mesma situação fática daqueles que conseguiram a resposta do Supremo, poderão não ter o seu direito efetivado. A isso Fernando Lima (2015, p. 190) denomina de atuação simbólica do STF, o "acesso obstaculizado pelo juízo de admissibilidade e não pelos julgados".

\section{CONCLUSÃO}

Quando se analisa a atuação do poder judiciário na implantação das políticas públicas e na efetivação dos direitos fundamentais previstos na Constituição, à primeira vista quer parecer que há uma confusão de poderes e que um não esteja cumprindo o seu papel, gerando uma desarmonia na interdependência entre os poderes Legislativo, Judiciário e Executivo.

Em judicialização dos direitos fundamentais e ativismo judicial é necessário compreender que o judiciário não está criando os direitos, pois estes já existem na 


\section{Personalidade Acadêmica Homenageada:}

Carlos Aurélio Mota de Souza (Universidade Ibirapuera - UNIB)

Constituição. Constata-se que as políticas públicas para aplicação dos direitos é que não são efetivamente implementadas pelo Executivo, deixando uma brecha ao Judiciário para agir.

Não se pode esquecer, porém, que muitas vezes ocorrem exageros do julgador, que se vê numa posição de salvador da pátria, aquele que pode resolver os problemas sociais do país. Ao se deparar com uma atuação pautada nessa premissa pode-se caracterizar afronta e risco à divisão dos poderes e comprometimento da concretização dos direitos à universalidade dos cidadãos. O judiciário quando atua no caso concreto, e agindo de forma exacerbada e ampliativa a um determinado grupo, acaba por excluir uma parcela da população do manto da efetivação dos direitos, aqui incluídos aqueles que não foram ao tribunal buscar o seu direito.

A produção de legislação simbólica, ao que se pôde analisar também é uma das formas de contribuir para a crescente judicialização e mesmo do ativismo judicial, que hoje cresce vertiginosamente.

Conclui-se que a questões de direitos fundamentais frente ao judiciário devem ser enfrentadas de forma macro, analisando o conjunto, em suas origens e consequências, buscando atingir resultados globais, não há que se falar em atuação simbólica, que é quando a Suprema Corte não se importa com as consequências de seus julgados. A atuação simbólica garante direito àquele que foi às portas do judiciário, mas faz pouco à efetivação do direito em caráter universal, como deve ser.

\section{REFERÊNCIAS}

ANDREASSA JUNIOR, Gilberto. Ativismo Judicial \& Teoria dos Precedentes. Integração dos Poderes e Coerência nas Decisões do Judiciário - Prefácio de Eduardo Talamini. Curitiba: Juruá, 2015.

BARROSO, Luís Roberto. O direito constitucional e a efetividade de suas normas: limites e possibilidades da constituição brasileira. 6 ed. Rio de Janeiro: Renovar, 2002.

BARROSO, Luís Roberto. Judicialização, ativismo judicial e legitimidade democrática. 2012. Disponível em: < http://www.cnj.jus.br/eadcnj/mod/resource/view.php?id=47743>. Acesso em: $15 \mathrm{dez}$. 2017. 
Personalidade Acadêmica Homenageada:

Carlos Aurélio Mota de Souza (Universidade Ibirapuera - UNIB)

BONAVIDES, Paulo. Do estado liberal ao estado social. 8 ed. São Paulo: Malheiros, 2007.

BRASIL, Deilton Ribeiro. Ativismo judicial e direitos fundamentais: leituras em Garapon e Ricoeur. Curitiba: Juruá, 2014.

. Constituição (1988). Constituição da República Federativa do Brasil: Senado Federal:

<http://www.planalto.gov.br/ccivil_03/constituicao/constituicao.htm>. Acesso em: 14 nov. 2017.

Constituição Federal Comentada. Coordenador: Célio Armando Janczeski. 1 ed. Curitiba: Juruá, 2011.

. Supremo Tribunal Federal. Recurso Extraordinário 368.564/DF. Relator Ministro Marco Aurélio. Requerente: União. Requerido: Maria Euridice de Lima Casale. Brasília, DF. Julgado em 13.04.2011. Publicado em 10.08.2011. Disponível em: <http://stf.jus.br/portal/jurisprudencia/listarJurisprudencia.asp?s1=\%28RE\%24\%2ES CLA\%2E+E+368564\%2ENUME\%2E\%29+OU+\%28RE\%2EACMS\%2E+ADJ2+3685 64\%2EACMS\%2E\%29\&base=baseAcordaos\&url=http://tinyurl.com/k59qe3j>. Acesso em: 16 nov. 2017.

. Supremo Tribunal Federal. Agravo Regimental na Suspensão de Liminar 47/ PE. Relator Ministro Gilmar Mendes. Agravante: Estado de Pernambuco. Agravado: União. Ministério Público Federal. Ministério Público do Estado de Pernambuco. Município de Petrolina. Brasília, DF. Julgado em 17.03.2010. Publicado em 30.04.2010. Disponível em: <http://stf.jusbrasil.com.br/jurisprudencia/9087061/agreg-na-suspensao-de-liminar-sl47-pe>. Acesso em: 16 nov. 2017.

FERREIRA, Eber de Meira. Poder judiciário, ativismo judicial e democracia. disponível em: <http://www.teses.usp.br/teses/disponiveis/2/2134/tde-08122014161522/pt-br.php>. Acesso em 09 jan. 2018.

LIMA, Fernando Rister de Sousa. Saúde e Supremo Tribunal Federal. Curitiba: Juruá, 2015.

LIMA, Vinicius de Melo. Teoria hermenêutica da responsabilidade decisória: direitos sociais entre ativismo judicial e decisão jurídica democrática. Curitiba: Juruá, 2016.

MONTESQUIEU. O espírito das leis. As formas de governo e a divisão dos poderes. São Paulo: Saraiva, 1987.

NEVES, Marcelo. A constitucionalização simbólica. 2 ed. São Paulo: WMF Martins Fontes, 2007. 
Personalidade Acadêmica Homenageada:

Carlos Aurélio Mota de Souza (Universidade Ibirapuera - UNIB) Fontes, 2008.

Entre Têmis e Leviatã: uma relação difícil. 2 ed. São Paulo: WMF Martins

A força simbólica dos direitos humanos. Revista Eletrônica de Direito do Estado, 2005, número 4. Salvador: Disponível em $<$ https://www.researchgate.net/publication/43921452_A_forca_simbolica_dos_direito s_humanos>. Acesso em: 09 jan. 2018.

RAMOS, Elival da Silva. Ativismo judicial: parâmetros dogmáticos. São Paulo: Saraiva, 2010.

SABINO, Marco Antônio da Costa. Saúde \& Judiciário - A Atuação Judicial - Limites, Excessos e Remédios - Biblioteca de Filosofia, Sociologia e Teoria do Direito Coordenação: Fernando Rister de Souza Lima. Curitiba: Juruá, 2016.

SARLET, Ingo Wolfgang; MARINONI, Luiz Guilherme; MITIDIERO, Daniel. Curso de direito constitucional. 5 ed. rev. e atual. São Paulo: Saraiva, 2016.

SCHWARTZ, Germano; BORTOLOTTO, Franciane Woutheres. A dimensão prestacional do direito à saúde e o controle judicial de políticas públicas sanitárias.

Disponível em:<https://www2.senado.leg.br/bdst/bitstream/handle/id/160191/Dimens\%C3\%A3o _prestacional_direito_saude_177.pdf?sequence=7>. Acesso em: 14 nov. 2016. 